\title{
Understanding the Perceptions of Chinese Aviation Maintenance Technicians Related to the Implementation and Use of 3D Aircraft Maintenance Manuals
}

\author{
Yu Wang and Steven Leib \\ Purdue University
}

\begin{abstract}
Aircraft maintenance manuals (AMMs) contain important information for the continued airworthiness of aircraft and are crucial technical documents for assuring maintenance tasks are carried out properly. However, because of mass text descriptions and static pictures, traditional AMMs have limited ability to show complicated aircraft structures and maintenance procedures accurately and intuitively. In order to improve the accuracy and descriptive ability of maintenance manuals to reduce misleading information and unclear procedures, a new style of aircraft maintenance manual, a three-dimensional (3D) maintenance manual, has been developed. Features of this manual include the use of 3D animations and multiple views to simulate component removal and installation processes. This type of manual can present short animations matched to individual steps of procedures. The purpose of this research project was to investigate how well the concept of a 3D maintenance manual could be accepted by front-line mechanics in the aviation industry and identify their perceptions about the usefulness of the traditional versus 3D maintenance manuals. This was a qualitative study that used surveys to assess the perceived benefits and drawbacks of both the traditional AMM and the 3D AMM. Participants were 48 front-line mechanics at multiple airlines in China. The results showed that the 3D AMM has the potential to be used for maintenance tasks and improve aircraft maintenance efficiency. In addition, along with the results, the study considered some recommendations for the improvement of 3D AMMs and suggested further research into understanding how maintenance technicians could utilize these documents more effectively.
\end{abstract}

\section{Introduction}

Aviation maintenance has always been a part of aircraft operations. Historically, information regarding maintenance processes has been relayed to aviation maintenance technicians via paper manuals. These manuals contain large amounts of text, diagrams, schematics, and step-by-step procedures. A single aircraft often requires multiple maintenance manuals, especially in the case of commercial aircraft. Recently, maintenance operations have begun to include alternative methods of disseminating this information to technicians, such as online manuals, PDFs, etc. As technology continues to advance, it is not impossible to have aviation maintenance manuals incorporate three-dimensional animations, as part of maintenance tasks. While the use of 3D maintenance manuals is in its infancy, much research needs to be conducted to understand the future of 3D 
maintenance manual development. This study aimed to understand one aspect of this development.

\section{Literature Review}

\section{Aircraft Maintenance Manual (AMM) Introduction}

Aircraft maintenance includes the processes of overhaul, repair, inspection and modification of an aircraft or aircraft component, which is necessary to maintain its airworthiness. Similarly, reliable maintenance documentation with accurate description plays a very important role in ensuring the proper maintenance of complex aviation equipment such as aircraft engines (Geng, Tian, \& Jia, 2011; Blue et al., 2002).

The International Air Transport Association (IATA) (2009) defines an aircraft maintenance manual as one that is "...produced and continuously updated by the aircraft manufacturer that contains procedures relating to the maintenance of aircraft, engines and components" (p. 15).

From a legal standpoint, the Federal Aviation Administration (FAA) imposes strict guidelines for the development and use of maintenance manuals. Federal Aviation Regulations (FARs) include several mandatory requirements for aviation organizations and operations that use manuals. According to the FARs (specifically 14 CFR $\$ 121.133$ [a]: Preparation) all air carriers are required to “...prepare and keep current a manual for the use and guidance of flight, ground operations, and management personnel in conducting its operations" (FAA, 1995, p.69). However, it is important to note that for the purpose of maintenance operations, Federal Aviation Regulations explicitly state that a paper manual is not the only allowable format: "...the certificate holder may prepare that part of the manual containing maintenance information and instructions, in whole or in part, in printed form or other form acceptable to the Administrator" (FAA, 1995, p.70).

As for the content of the maintenance manual, Federal Aviation Regulations also prescribe specific requirements as to what information should be included in all manuals: "Airworthiness inspections, including instructions covering procedures, standards, responsibilities, and authority of inspection personnel" (FAA, 2007, p.71) all must be incorporated.

Further investigation into the purpose and usage of aircraft maintenance manuals reveals a surprising amount of depth to how they are developed and utilized. Several research projects regarding maintenance documentation have shown the importance of aircraft maintenance documentation to ensuring safe operations.

In 2001, the FAA conducted a study focusing on aviation maintenance errors. The purpose of the study was to identify categories of human error related to installation during maintenance. Upon completion of the six-month study, researchers found that the failure 
to comply with technical maintenance documents was the primary contributing factor to maintenance errors. This study also referenced a company-wide intervention program, "Key Behaviors for Aircraft Maintenance \& Hangar Inspection." The original objective of this program was to ensure that the engineering department and maintenance-related management provide mechanics with appropriate maintenance documentation (Johnson \& Watson, 2001).

According to Avers, Johnson, Banks, and Wenzel (2012), the NASA Aviation Safety Reporting System indicated that 9,000 of 14,267 (approximately 64\%) safety incidents coded in maintenance reports from 2001 to 2011, resulted from technical documentation or maintenance procedures or both.

\section{Virtual Reality Introduction}

Virtual Reality (VR) refers to a technology that is regarded as a natural extension to 3D computer graphics with advanced input and output devices. It has been regarded as a simulated 3D environment based on a computer, in which one can use a standard input tool (a key board or mouse) to operate objects. A 3D modeling software program can be used to create a model of the object that can be shown on the screen. The display technology can range from the basic display, a computer monitor, to the specialized head-mounted displays (HMD). To put it simply, virtual reality can be defined as a virtual environment where one can have a feeling of "being there" (Jataram, Connacher, \& Lyons, 1997; Thalman \& Thalman, 2003).

Virtual reality systems can work in a variety of forms and have applications in different industries (Brooks, 1999). Some applications, for example, include design review of an electric boat, astronaut training at NASA, merchant ship simulation, and flying a Boeing 747. Applications of VR also have a major influence on enhancing productivity and efficiency, improving team communication, and reducing costs.

Druck (2006) also pointed out the wide applications of VR systems in different industries. Virtual reality technology has become an exceedingly useful approach for engineers, researchers, scientists and manufacturers to improve product quality, design productivity and maintainability. There are applications of VR from entertainment to scientific visualization and from three-dimensional walkthroughs to real-time prototyping. VR technology also can be found in training, from flight simulators to surgery.

\section{Virtual Reality in Maintenance Manuals}

According to Geng, Tian, and Jia (2011), even though people have realized the importance of timely and proper maintenance, and the quality of maintenance in the aviation industry has been improved, traditional aircraft maintenance manuals (paperbased manuals) still have some drawbacks. For one, mass text descriptions and static

pictures cannot demonstrate assembly and disassembly procedures clearly, intuitively, and 
accurately. There is still some misleading and ambiguous information that can lead to misunderstanding by front-line mechanics performing maintenance processes. This, as a consequence, might result in lower-quality maintenance, wasted time, and lost efficiency.

Avers, Johnson, Banks, and Wenzel (2012) proposed the concept of next-generation maintenance technical documentation. The current technical documentation does not have regulatory specification on media, format, turn-around times, etc. The next-generation technology (3D modeling, embedded video training, voice recognition, etc.) could allow engineers and mechanics to have access to the proper maintenance information conveniently. In the aviation industry, with the help of advanced technology, the goal of delivering the right form of maintenance information into the right hands at the right time and place is feasible.

Although there are many accomplishments of virtual reality in different arenas, VR technology has not been widely used in aviation maintenance. In recent times, an increasing number of experts, professors, and aviation maintenance-related organizations have realized the huge potential for VR implementation in aviation maintenance, especially in aviation maintenance manuals (Avers, Johnson, Banks, \& Wenzel, 2012).

Based on the concept of virtual reality, Zhu, Tan and Wei (2010) pointed out the high application potential of 3D maintenance documents. They took the horizontal stabilizer of an aircraft as an example and utilized a 3D maintenance manual to show the procedures of virtual assembly. They concluded that 3D maintenance documents are able to clearly illustrate simulation processes with 3D animations, texts and 3D annotation. Illustrative texts can work together with 3D animations to provide an accurate description of maintenance processes. Intuitive animations make it easier for maintenance crews to understand assembly and disassembly processes compared to the text-only description. Thus, 3D maintenance manuals can, to a great degree, avoid ambiguity and provide a clearer illustration of maintenance processes in order to enhance the efficiency of assembly and disassembly.

Chaparro and Groff (2002) conducted a 3-phase research project to identify human factors in the improvement of aviation technical manuals and offered some recommendations for the improvement of aircraft maintenance documentation in their report. They found that the primary concern about maintenance manuals shared by most users turned out to be usability. Improving the usability of documents can enhance users' satisfaction level on maintenance manuals, decrease the maintenance cost, and ensure efficient maintenance tasks.

Chaparro and Groff (2002) also pointed out that there is a slow but steady trend to take the place of paper-based manuals with computer-based maintenance manuals. Computerbased manuals, including text, audio, and video-based media, can provide technicians and mechanics with a comprehensive, detailed and clear description of maintenance processes. Electronic documents can also be updated and distributed easily, take up less space, and 
allow mechanics to have access to information conveniently. Thus, the transition from paper-based manuals to electronic manuals could address many usability problems.

All in all, the information mentioned previously has indicated the implementation potential of 3D maintenance manuals in aviation maintenance operations. But how frontline workers are willing to utilize the new style of maintenance documents has yet to be fully understood. The purpose of this project was to obtain the front-line mechanics' perceptions and attitudes toward the implementation of 3D aircraft maintenance manuals and collect recommendations on the improvement of 3D maintenance documents.

\section{Statement of the Problem}

Regardless of the actual benefits provided by 3D maintenance manuals, their successful growth in the maintenance environment is rooted in the acceptance of those who would be using them. Research has yet to address the perceptions and attitude of aviation maintenance technicians themselves. How these individuals perceive the benefits of 3D maintenance manuals can provide much insight as to their course of implementation.

\section{Research Questions}

This study specifically intended to focus on the perceptions and attitudes of front-line aviation maintenance technicians who have had experience with paper-based manuals. Because these individuals would be the primary users of 3D aviation maintenance manuals, this study posed the following research questions regarding their perceptions about 3D manuals:

1. What are the perceptions of Chinese front-line aviation maintenance technicians toward the challenges and benefits associated with current paper-based manuals?

2. What are the perceptions of Chinese front-line aviation maintenance technicians toward the challenges and benefits associated with 3D-based manuals?

3. What are the attitudes of Chinese aviation maintenance technicians toward the future incorporation of 3D-based manuals into aviation maintenance operations?

\section{Methodology}

\section{Research Type and Framework}

This was a qualitative study that utilized a survey tool to understand the perceptions and attitudes of participants working at maintenance operations in China. Specifically, this project measured their responses regarding the benefits and challenges of both traditional paper manuals and 3D manuals, as well as the potential future incorporation of 3D manuals in an aviation maintenance operation in the Chinese culture. This project was supported by a university's Institutional Review Board (IRB). 


\section{Sample}

There were 48 survey participants in this research study. Participants were front-line maintenance technicians certificated by the CAAC at multiple Chinese airlines. All participants were full-time front-line mechanics performing aircraft maintenance and repair tasks. Participants were contacted by emails and volunteered to participant in this study through an online survey.

\section{Data Collection}

An online survey was designed using Qualtrics (online survey software). This survey included a demonstration of the computer-based and animated 3D maintenance manual showing the removal process of the main oil/fuel heat exchanger. Solidworks and Cortona3D software were used by the researchers to design the demo of the 3D maintenance manual (see Figure 1). Eight qualitative questions based on a comparison between 3D and paper-based maintenance manuals were provided in the survey (see Appendix).

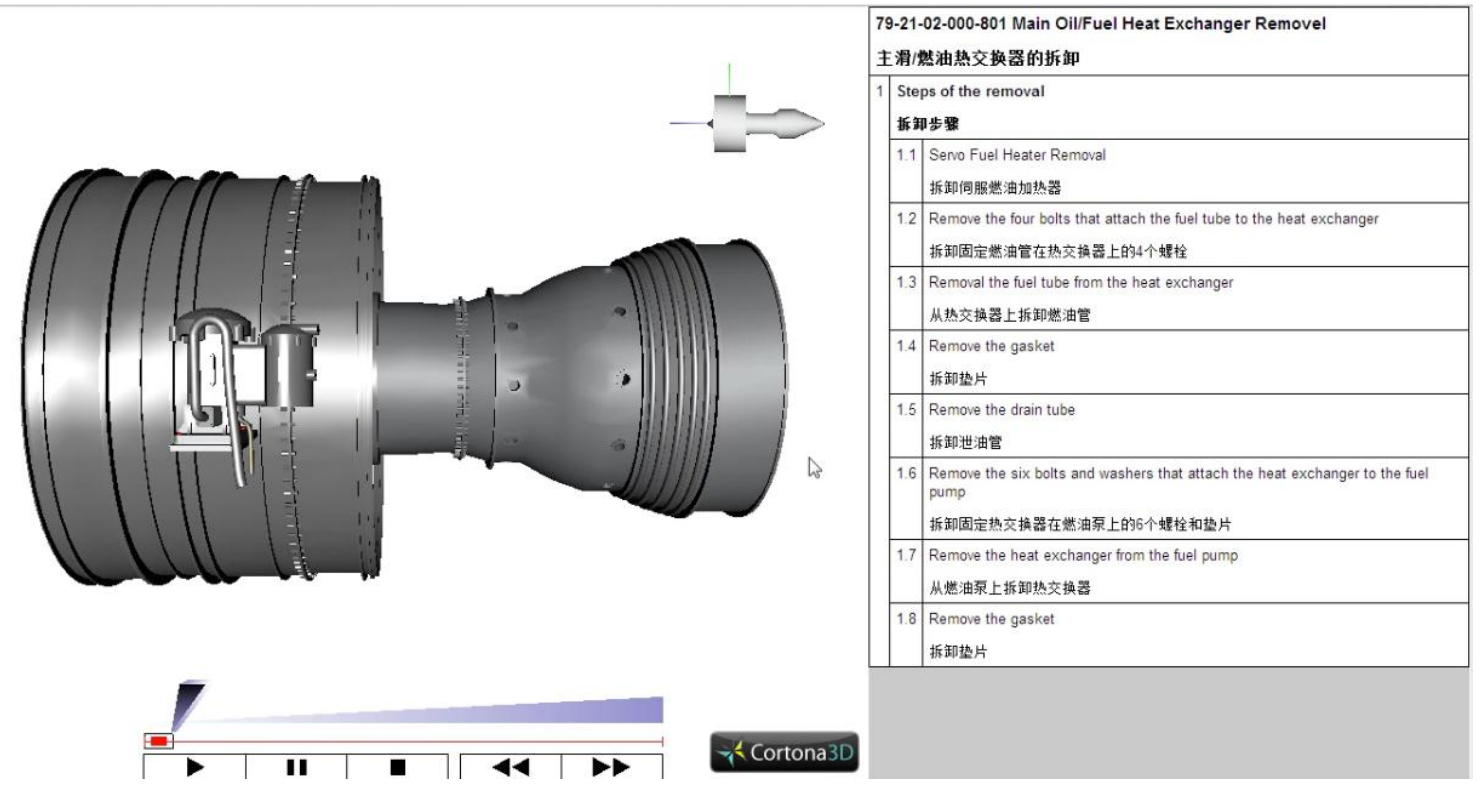

Figure 1. Static image from the demo of the 3D maintenance manual (developed from Solidworks and Cortona3D software)

\section{Results}

Forty-eight respondents from multiple Chinese airlines participated in the survey. Data analysis was carried out by coding their responses into common themes. The data was then grouped into three categories that respectively answered the three research questions, 
which will be discussed in the following section. They include: challenges of paper-based and 3D manuals, benefits of paper-based and 3D manuals, and respondents' acceptance of 3D manuals.

\section{Challenges of Paper-based and 3D Manuals}

With regard to the drawbacks of using paper-based manuals, the survey participants expressed concerns about fragility. One of main concerns was that paper manuals could become damaged easily. In addition, data collected indicated that because of lack of a retrieve function, searching desired content from a great deal of information from paper manuals might be a very time-consuming task. The low efficiency of locating useful information is a significant challenge for paper-based manuals. Furthermore, according to the feedback from front-line maintenance technicians, paper manuals are not environmentally friendly.

Regarding the challenges of 3D maintenance manuals, most of the respondents pointed out that the utilization of 3D maintenance manuals needs hardware support. In other words, in contrast to paper-based manuals, users need to use electronic equipment to display 3D maintenance manuals, which may not be convenient for use at a maintenance worksite. This is especially a concern in a poor maintenance work environment, such as wet or cold. In addition, $25 \%$ of respondents also appeared to have concerns about the cost of development of 3D maintenance manuals. These concerns were related to the complexity of aircraft systems, higher technical requirements, and that a greater amount of manpower involved might increase the cost of 3D manuals' development, design and revision. Another challenge pointed out by the respondents was regarding the accuracy of 3D maintenance manuals. Due to the complexity and diversity of aircraft structures, keeping the information displayed by $3 \mathrm{D}$ animations accurate could be very challenging.

\section{Benefits of Paper-based and 3D Manuals}

Regarding the merits of using paper manuals, the most frequent response received from participants was that paper manuals are "easy to use" [translated]. Responses indicated that paper manuals can easily be taken to jobsites and technicians can access them easily from the toolboxes during maintenance tasks. Additionally, $42 \%$ of respondents believed that paper manuals are good for eyesight and are very readable. Another benefit of using paper manuals reported by participants was that front-line maintenance technicians or mechanics are able to make notes and mark on paper manuals easily.

According to the comments from the respondents about the merits of 3D maintenance manuals, the biggest benefit of utilizing 3D manuals is that 3D animations are able to provide a clear, visual and direct overview of assembly and disassembly procedures. Technicians can experience real-time maintenance procedures just by seeing the 3D animations. In addition, responses indicated the visualization of maintenance procedures would lead to an easier and better understanding of the maintenance tasks for front-line 
technicians and mechanics, as compared to paper-based manuals. In terms of maintenance efficiency, all the respondents also gave positive comments about the potential improvement on the efficiency of maintenance tasks. In addition, most respondents commented that the ease and clarity of 3D maintenance manuals could help to reduce mistakes in interpreting the procedures and performing the tasks. Because of the additional features afforded by 3D animation software, 3D animations have the power to make specific and complicated maintenance steps more easily understood, so that the task can be completed more efficiently and effectively.

\section{Respondents' Acceptance of 3D Manuals}

The data collected indicated that participants were not only willing to adopt 3D maintenance manuals in their operation, but also were willing to encourage superiors to develop 3D maintenance manuals. Thirty-six out of forty-eight respondents had prior experience with various aspects of digital media for maintenance manuals, including online manuals and PDF documents, which suggested their openness to other forms of maintenance manuals. More importantly, all participants indicated explicitly that the incorporation of 3D maintenance manuals to aviation operations is a worthy pursuit. This finding can be seen from the participants' answers to the seventh survey question: "Overall, do you feel the incorporation of 3D maintenance manuals to aviation operations is worth pursuing?" All the 27 participants who completed this question provided a positive answer.

\section{Discussion}

As mentioned previously, all of the participants appreciated the value of incorporating 3D maintenance manuals in future operations. Participants acknowledged and appreciated the advantages that 3D manuals provide over paper-based manuals for the purposes of education/training, efficiency, and ease of use. The findings from this study suggest that 3D maintenance manuals could, to some degree, help mechanics learn the component removal processes more effectively, compared to $2 \mathrm{D}$ maintenance manuals. Plus, $75 \%$ of respondents already had some experience with alternative media for aviation maintenance information sharing. In other words, airlines, aircraft manufacturers and other aviationrelated organizations have already started to establish and utilize different forms of maintenance manuals in the aviation maintenance operations. This also indicated maintenance technicians' openness to other forms of information presentation to accomplish maintenance tasks.

In addition, respondents identified several challenges and benefits associated with the use of 3D manuals. Based on their comments and suggestions regarding these benefits and challenges, it seemed participants' responses indicated uncertainty about the specific timeline of adoption of 3D manuals, but clearly expressed their expectation that 3D manuals would be incorporated into aviation maintenance operations. For example, one respondent stated," the 3D maintenance development is a long-term but rewarding project." [translated]. Across all participants, there was no indication that 3D maintenance manuals 
had no future in the aviation industry, or that the implementation of 3D maintenance manuals was a fruitless endeavor. Furthermore, there were no comments about specific challenges that indicated they could not be mitigated or resolved. However, several challenges of utilizing 3D maintenance manuals pointed out by the survey participants might need to be addressed in future studies, to better understand how 3D maintenance manuals could be used in future maintenance operations. Some possible recommendations for how to address the challenges of 3D manuals will be suggested in the next section.

More importantly, along with the data collection, the survey participants also provided some valuable recommendations and suggestions on the future implementation of 3D maintenance manuals into the aviation industry. For example, "multiple parties should be involved to develop 3D maintenance manuals" [translated]. This pointed out a very important success factor of the future implementation of 3D maintenance manuals in the aviation operations - a multi-party cooperation. According to the survey participants, developing a user friendly, powerful and accurate 3D maintenance manual is a long-term project, which cannot be achieved successfully without a strong collaboration from multiple parties. Based on the recommendations of respondents: aircraft manufacturers, airlines, aviation authorities, and other aviation maintenance-related organizations should be supportive on the design and development of this new style of maintenance manuals.

This study had several limitations that must be acknowledged. For one, the small sample size, to some degree, could restrict this project from drawing a more reliable conclusion. Additionally, survey participants of this research project were technicians from Chinese airlines. The results received from this research project may not be generalizable to other countries' maintenance technicians. For example, maintenance technicians working at airlines in the United States may have different thoughts about the implementation of 3D maintenance manuals in the aviation industry. Additionally, individuals from different age groups may have different views about new technology. Compared with older individuals, young people may have had more chances to utilize computer technology, and their direct experience with technology could impact the study. Therefore, it might be easier for young technicians to adjust to the advent of 3D maintenance manuals, than for experienced technicians who have been using traditional manuals for years and may or may not like to change the existing maintenance operations.

\section{Conclusions and Recommendations}

The main purpose of this research was to determine the perceptions of front-line maintenance technicians toward the implementation of $3 \mathrm{D}$ maintenance manuals into aviation operations. As discussed above, participants not only were willing to adopt the new style of manuals, but also encouraged the incorporation of 3D maintenance manuals into the aviation industry. In addition, according to the responses, 3D maintenance manuals appeared to have certain advantages over 2D maintenance manuals in the respects of ease of use, maintenance efficiency and, training. Although participants also recognized 
disadvantages to adopting 3D manuals, those disadvantages did not appear to outweigh the benefits, and there was overall strong support for 3D manuals.

There are several recommendations that can be discussed based on this research study. For one, there are a lot of opportunities to empirically measure and statistically compare aspects of improved efficiency and speed that accompany the use of 3D manuals as suggested by the results of this study. In the future, some research projects could focus on using quantitative methods to demonstrate a comparison between 3D maintenance manuals and 2D maintenance manuals regarding efficiency, accuracy and effectiveness. Some metrics, for example, could be the number of errors made by technicians in a certain amount of time, the overall time spent on certain tasks, and other comparative aspects between 3D manuals and 2D manuals.

Another recommendation for future research is to expand the sample size and include participants from different countries. In addition, future researchers could also take age as a consideration regarding the respondents' acceptance of 3D manuals. To include the influence of age in the data analysis about the acceptance of 3D maintenance manuals might be an interesting research aspect.

Additionally, some recommendations can also be made to address the challenges of using 3D manuals. For example, addressing the respondents' concern about the accuracy of 3D maintenance manuals might mean 3D maintenance manuals can be implemented as a complement to the paper-based or printed manuals. Text and animations can be used together at the beginning stages of 3D maintenance manual use. Then, when inaccurate information is found while using 3D maintenance manuals, programmers can update and correct it to improve the manuals' efficiency and accuracy. With regard to another challenge, 3D manuals are not easily taken to maintenance jobsites, because hardware support is required. However, the 3D maintenance manuals can be displayed by small and portable electronics, such as smart phones and tablets. These electronics can be more easily taken to the maintenance work sites. Lastly, regarding the challenges of the cost of 3D manual development, cooperation and information sharing among airlines, aircraft manufacturer and aviation authorities could reduce the cost to some extent of 3D maintenance manual development and updates as compared to relying on one entity. 


\section{References}

Avers, K., Johnson, B., Banks, J., \& Wenzel, B. (2012). Technical Documentation Challenges in Aviation Maintenance: A Proceedings Report. Washington, DC. DOT/FAA/AM-12/16.

Blue, R. S., et al. (2002). An automated approach and virtual environment for generating maintenance instructions. In Conference on Human Factors in Computing Systems: CHI'02 extended abstracts on Human factors in computing systems (Vol. 20, No. 25, pp. 494-495).

Brooks Jr, F. P. (1999). What's real about virtual reality? Computer Graphics and Applications, IEEE, 19(6), 16-27.

Chaparro, A., \& Groff, L. S. (2002). Human factors survey of aviation maintenance technical manuals. Proceedings of the 16th Human Factors in Aviation Maintenance Symposium. San Francisco, CA.

Druck, A. (2006). When will virtual reality become a reality? Retrieved from http://techcast.org/Upload/PDFs/061026231112TC\%20\%20Aaron.pdf

FAA. (1995). Federal Aviation Regulations. $§ 121.133$ Preparation. Retrieved from http://www.gpo.gov/fdsys/pkg/CFR-2012-title14-vol3/pdf/CFR-2012-title14vol3-sec121-133.pdf

FAA. (2007). Federal Aviation Regulations.§ 121.135 Manual contents. Retrieved from http://www.gpo.gov/fdsys/pkg/CFR-2012-title14-vol3/pdf/CFR-2012-title14vol3-sec121-135.pdf

Geng, J. H., Tian, X. T.,\& Jia, X. L. (2011). Aviation equipment maintenance job card generation method based on lightweight model. Advanced Materials Research, 201, 714-717.

IATA. (2009). Technical Reference Manual. Retrieved from http://www.iata.org/sitecollectiondocuments/documents/itrmed1rev1.pdf

Jayaram, S., Connacher, H. I., \& Lyons, K. W. (1997).Virtual assembly using virtual reality techniques. Computer-Aided Design, 29(8), 575-584.

Johnson, W. B., \& Watson, J. (2001). Reducing installation error in airline maintenance. Federal Aviation Administration/Office of Aviation Medicine, Washington, DC. 
Thalmann, N. M., \& Thalmann, D. (2003). Virtual reality software and technology. Proceedings of the ACM Symposium on Virtual Reality, Software and Technology. Osaka, Japan.

Zhu, W. H., Tan, H. M., \& Wei, P. G. (2010). Studies on virtual assembly process system. In Audio Language and Image Processing (ICALIP), 2010 International Conference on (pp. 1637-1642). IEEE. 


\section{Appendix}

Survey Questions for Study Participants

1. Please comment on the benefits of paper manuals in your operation.

请简述纸质版维修手册的优点。

2. Please comment on the issues (drawbacks) with using paper manuals in your operation. 请简述纸质版维修手册存在的问题（劣势）

3. Do you have experience with alternative media for aviation maintenance information sharing? If yes, please elaborate.

你是否接触过其他形式，非纸质版的维修文件。如果有，请详细说明

4. Please comment on the benefits and challenges of 3D manuals for the aviation maintenance community for the purpose of EDUCATION/TRAINING.

请说明3D维修手册在教育或者培训方面的优势和挑战

5. Please comment on the benefits and challenges of 3D manuals for the aviation maintenance community for the purpose of EFFICIENCY?

请说明3D维修手册在维修效率方面的优势和挑战

6. Please comment on the benefits and challenges of $3 \mathrm{D}$ manuals for the aviation maintenance community for the purpose of EASE OF USE.

请说明3D维修手册在易用性方面的优势和挑战

7. Overall, do you feel the incorporation of 3D maintenance manuals to aviation operations is worth pursuing?

总体来讲, 你是否认为3D维修手册在航空产业的应用是有意义的?

8. Please provide any additional comments relevant to the development and use of $3 \mathrm{D}$ maintenance manuals in aviation.

请针对3D维修手册在航空产业的应用和开发，提出其他相关的意见和建议。 